Kai A. Konrad

\title{
Opinion Leaders, Influence Activities and Leadership Rents
}

\author{
WZB - Wissenschaftszentrum Berlin
}

SP II $2003-29$

December 2003

ISSN Nr. $0722-6748$

Research Area

Markets and Political Economy

Research Unit

Market Processes and Governance
Forschungsschwerpunkt

Markt und politische Ökonomie

Abteilung

Marktprozesse und Steuerung 
Zitierweise/Citation:

Kai A. Konrad, Opinion Leaders, Influence Activities and Leadership Rents, Discussion Paper SP II 2003 - 29, Wissenschaftszentrum Berlin, 2003.

Wissenschaftszentrum Berlin für Sozialforschung gGmbH, Reichpietschufer 50, 10785 Berlin, Germany, Tel. (030) 25491 - 0 Internet: www.wz-berlin.de 


\section{ABSTRACT}

\section{Opinion Leaders, Influence Activities and Leadership Rents}

by Kai A. Konrad*

Consumers may observe previous consumers' choices. They may follow their choices if they think these consumers are better informed. In turn, firms may concentrate on influencing the early consumers. This, in turn, changes the nature of early consumers' choice behavior as a signal for other consumers. In this paper, I show that firms' influence activities need not distort earlier consumers' decisions, but may reduce the informative value of these decisions for other consumers if influence activities are noisy or if some firms have deep pockets and others are liquidity constrained.

Keywords: Opinion leaders, influence activities, promotional competition, leadership, deep pockets, liquidity constraints

JEL Classification: D43, D72, L15

\section{ZUSAMMENFASSUNG}

\section{Konsumentenbeeinflussung und die Konsumentenrenten von Meinungsführern bei Produktinnovationen}

Wenn die Kaufentscheidungen früher Konsumenten von nachfolgenden Konsumenten beobachtbar sind, können frühe Kaufentscheidungen von wohlinformierten Konsumenten auch informativ für nachfolgende Konsumenten sein und diese zur Imitation früher Kaufentscheidungen veranlassen. Unternehmer haben deshalb bei Produktinnovationen einen Anreiz, das Kaufverhalten früher Konsumenten durch Preisnachlässe oder Werbegeschenke zu beeinflussen. Aus diesen Vergünstigungen resultiert für die frühen Konsumenten eine Konsumentenrente. Die Vergünstigungen verändern aber auch den Informationswert der Kaufentscheidung früher Konsumenten. In dem Beitrag wird gezeigt, dass die frühen Konsumenten im Gleichgewicht aus den Vergünstigungen eine erhebliche Rente erhalten, ihre Kaufentscheidung aber durch die Vergünstigungen nicht beeinflusst wird und als Signal für nachfolgende Käufer informativ bleibt. Das gilt vor allem, wenn die Beeinflussungsaktivitäten der Unternehmen effizient sind (z.B. in Form von Preisnachlässen erfolgen), und wenn die konkurrierenden Unternehmen ex-ante in einer symmetrischen Wettbewerbssituation sind. Der Beitrag untersucht zudem die Rolle von Budgetbeschränkungen der Unternehmen. Diese erweisen sich für das budgetbeschränkte und für das konkurrierende Unternehmen als vorteilhaft. Asymmetrische Budgetbeschränkungen senken aber die Effizienz des Marktergebnisses.

\footnotetext{
* I thank Helmut Bester, Kjell Erik Lommerud and Robert Nuscheler for discussion and comments. The usual caveat applies.
} 


\section{Introduction}

In many markets, consumers differ regarding their information about how valuable is one firm's product compared to that of another firm. Well informed consumers may then act as opinion leaders and market makers. As they have superior information, they cannot learn from watching others, and may as well choose early. ${ }^{1}$ If other consumers can observe their choices, these other consumers may learn from their choices, and it may be worthwhile to imitate these choices. Early consumers' choices may, hence, determine the choice of all further consumers, a phenomenon that has been studied extensively as herd behavior or as information cascades. ${ }^{2}$

A consequence of this is that opinion leaders determine the allocation of producer rents. Their decision can determine which producer serves the whole market. Producers are aware of the importance of the market making function of opinion leaders. Producers may therefore try and influence these opinion leaders' consumption choices. They are willing to pay for attracting the consumption choice of the opinion leader, and their willingness to pay is mainly determined by the profit to be made on the whole market that can be gained by attracting opinion leaders.

If the information spillovers from early consumers to subsequent consumers exist, one should therefore expect to observe considerable influence activities, targeted at early consumers. Indeed, the literature on diffusion of innovations has identified the special role of opinion leaders (see, e.g., Rogers 1983, Valente and Davis 1999) in accelerating diffusion processes by word of mouth and by imitation of the opinion leader. ${ }^{3}$ The empirical literature also establishes that the information status of an agent is a key factor in whether the agent becomes an opinion leader. ${ }^{4}$ Further, these opinion leaders are targets of producers' influence activities. The marketing literature has emphasized the importance of advertising and sales via opinion leaders, and textbooks devote chapters on how such strategies could be put in place.

\footnotetext{
${ }^{1}$ This is indeed the equilibrium outcome in a waiting game in which all consumers may get different signals about products. An analysis parallels the line of arguments in Bliss and Nalebuff (1986).

${ }^{2}$ The seminal papers on herd behavior are Bikhchandani, Hirshleifer and Welch (1992) and Bannerjee (1992).

${ }^{3}$ Leonard-Barton (1981), for instance, studied the adoption of residential solar water heating. She reported that the strongest predictor of a resident's intention to buy was the number of owners of this technology known by the resident.

${ }^{4}$ See, for instance, Grewal, Mehta and Kardes (2000), who study car markets and computer markets. They report that expertise and opinion leadership are significantly positively correlated in these markets and conclude that experts tend to become opinion leaders, or that expertise is an antecedent of both innovativeness and opinion leadership.
} 
Bribes, gifts, or special rates play a major role as influence activities in this context. Wilkie (1986, p.163), for instance, writes: "This strategy requires locating the socially integrated and socially independent consumers for a particular product category and then promoting the product especially to them, even giving it to them free." Wilkie also reports a case study where particular rock music records were successfully promoted by handing out packages of records for free to a "select panel" of leaders, asking them for their evaluations. Similarly, many products which involve some quality uncertainty, sell with a discount when first introduced in the market. For instance, aircraft manufacturers grant considerable discounts on early orders when launching a new type of aircraft..$^{5}$

Ernest Dichter (1966) already summarized the marketing strategy of a firm using opinion leaders: to identify opinion leaders, and to make them promote the firm's products. But Dichter also acknowledges the basic tradeoff associated with marketing strategies that target opinion leaders. Dichter (1966, p. 157) argues that information transmission from opinion leaders to followers works if, and because, the rewards of the leader are purely psychological and never material: "This very assumption - that no material interest is involved in the recommendation - is the most basic motivation for the "listener' in accepting and acting on the recommendation." Influence activities that affect the choice behavior of opinion leaders may distort the signal that their undistorted choice would give to other consumers, and may make their choice less valuable as an indicator of product quality.

To illustrate: if a new restaurant opens up, the decision of the first few customers may induce an information cascade, making all consumers follow the quality signal that can be deduced from the choices of the early consumers who make one restaurant crowded and look popular. Hence, the restaurant owners are motivated to influence the decision making, particularly of early consumers who could induce herding. More precisely, the restaurant owners may bribe the customers during an opening period. However, does this strategy work if other consumers know that these early consumers are bribed?

The theory developed here also applies to examples where some individuals are opinion leaders (for whatever reason) and generate one fashion or another, or bandwagon effects because their choice behavior is imitated. Such agents are prime targets for influence activities, because their decision is imitated by a large set of individuals, and hence, their decisions allocate a multiple of the rents they actually generate as the direct consequences of their own behavior. However, if later consumers consider imitating their opinion

\footnotetext{
${ }^{5}$ When Airbus Industries launched its new mega-size aircraft A 380, discounts on early orders were up to 40 percent (Business Week, March 5, 2001, p.20).
} 
leaders and know that their decisions were based on superior information, but also on bribes, should they still imitate them, or perhaps trust their own judgement?

Summarizing, the research question in this paper is as follows. In the absence of influence activities, consumers with superior information become opinion leaders whose choices are imitated by other consumers. The leaders' decisions allocate large amounts of producer rents. Firms should therefore have an incentive to influence the decisions of opinion leaders. But this influence may weaken their leadership. If an opinion leader is known to make a consumption choice because he was bribed to make this choice, the informational value of his choice may be discounted or eliminated. This, in turn would make the influence activity less profitable, or even useless. The central question this paper is whether influence activities occur, how they influence the decision process, and how they allocate rents. Will the better informed consumer who decides first and who may induce an information cascade earn a rent? Will influence activity be able to destroy the signal that is provided by the first consumer's choice? It will turn out that the answers depend on the quality of the mechanism through which influence activity affects decisions, and on symmetry properties of the producers. As the amounts producers would want to spend on influence activities in the equilibrium in a market early on are considerable, deep pockets and liquidity constraints are of particular importance. Liquidity constraints turn out to be a useful commitment device, particularly if all producers are constrained, but they benefit producers even if not all producers face liquidity constraints.

The main framework and a benchmark case is set out in the next section. Section 3 considers deviations from this benchmark, concentrating in particular on noisy bribes and on the benefits of liquidity constraints or deep pockets. Section 4 concludes.

\section{The opinion leadership framework}

I consider two firms producing goods $a$ and $b$, respectively. Further, there are $n$ consumers, indexed by $i$. Each of these consumers decides whether to buy one unit of good $a$, one unit of good $b$, or nothing at all. Consumer 1 ('she') chooses first; all other consumers choose later. ${ }^{6}$

Firms' per-unit production cost is normalized to zero, and there are no

\footnotetext{
${ }^{6}$ This exogenous timing is for simplicity only. Given the assumptions about consumers' product information and about the observability of buying decisions, this timing could also emerge endogenously in an equilibrium. But to describe explicitly the waiting game that leads to this outcome is an unnecessary complication.
} 
capacity constraints. Firms first choose the price of their product charged to consumer 1. As will turn out, this price will typically be negative in the equilibrium, as it includes an element of bribes. I will denote what the firms pay to consumer 1 (net of any price received from the consumer) if she purchases the firm's product as $s_{a}$ and $s_{b}$, respectively, and I will denote these net transfers from producers to consumer 1 as 'bribes'.

Prices for other consumers are chosen when consumer 1 has made her choice. These prices will be $p_{a}$ and $p_{b}$, respectively, and the rationale that guides the choice of these prices is explained in detail below.

Coming to the consumers: there is some uncertainty about the consumers' valuation of the products $a$ and $b$. All consumers have the same tastes in the sense that their valuations of the two goods are identical. However, there are two states of the world. In state $A$ all consumers attribute a value of 1 to good $a$ and a value of 0 to good $b$. In state $B$ all consumers attribute a value of 0 to good $a$ and a value of 1 to good $b$. The state of nature is uncertain and producers and all consumers $i=2, \ldots n$ attribute ex ante equal probabilities to the two states. However, consumer 1 privately receives an informative signal. This signal changes her belief that state $A$ occurs to $\theta \in(0,1)$, where $\theta$ is a random variable that, for simplicity, is assumed to be uniformly distributed on the unit interval. I will assume that only the opinion leader observes the signal. The producers and the consumers $i=2, \ldots n$ do not.

The consumer 1 has an information advantage compared to other consumers, and chooses first. As her choice is observable and may affect other consumers' choices, I will call her the opinion leader. Consider her choice now. If she chooses $a$, the firm $a$ pays her $s_{a}$. If she chooses $b$, firm $b$ pays her $s_{b}$. The opinion leader can choose at most one of the products.

As firms try to influence her behavior in order to change future consumers' behavior, they will try to hide the size of their bribes; therefore I will assume that all other consumers $i=2, \ldots n$ cannot observe the value of the bribes offered to consumer 1 .

The incentive to pay the bribe in a clandestine way may also imply that there could be some value loss in the transfer from the firm to the customer, and I assume that what she receives has a monetary value of $s_{a}-\epsilon_{a}$. Similarly, if $b$ 's bribe $s_{b}$ were paid to her, its value for her would be $s_{b}-\epsilon_{b}$. Here $\epsilon_{a}$ and $\epsilon_{b}$ are random variables, and I will assume that $\epsilon_{a}-\epsilon_{b}$ is a random variable that is uniformly distributed on the interval $[-e, e]$. In this section the benchmark case in which there is random element, $\epsilon_{a}=\epsilon_{b}=0$ is considered. The importance of noise its various intuitive interpretations will be discussed in greater detail in section 3 .

Once the opinion leader has chosen one or the other product, the producers choose the price that applies to all other consumers $i=2, \ldots n$. These 
prices are denoted $p_{a}$ and $p_{b}$, respectively. These further consumers will not be bribed. ${ }^{7}$ Other consumers observe consumer 1's choice, but not her true consumption benefit or the bribe. They may, or may not, learn something from her choice - that is, she may, but need not, really become an opinion leader. Then the consumers $i=2, \ldots n$ make their consumption choice simultaneously. This simultaneity is not needed for the results if the consumers $i=2, \ldots n$ do not have private information. However, the simplification will be useful when considering the case in which these consumers also have some private information.

I will first consider a benchmark in which there is no noise.

Proposition 1 For $\epsilon_{a}=\epsilon_{b} \equiv 0$ and $n \geq 3$ there is a perfect Bayesian equilibrium such that consumer 1 receives bribes $s_{a}=s_{b}=\frac{n-1}{2}-1$ and always chooses $a$ or $b$ according to her signal, the firm $j \in\{a, b\}$ whose product was chosen by consumer 1 chooses a price equal to $p_{j}=1 / 2$, the other firm chooses a price equal to zero, and all further consumers imitate consumer 1 's choice. In this equilibrium, total expected rent is

$$
n E[\max \{\theta, 1-\theta\}]=\frac{3}{4} n .
$$

Consumer 1 receives an expected rent equal to

$$
E[\max \{\theta, 1-\theta\}]+\frac{n-1}{2}-1=\frac{n-1}{2}-\frac{1}{4}
$$

and each consumer $i=2, \ldots n$ receives an expected rent equal to

$$
E[\max \{\theta, 1-\theta\}]-\frac{1}{2}=\frac{1}{4} .
$$

Each producer receives an expected producer rent equal to $\frac{1}{2}$.

Proof: Consider first the consumers $i=2, \ldots n$. Their expected payoffs from buying good $a$ or $b$ depend on their posterior beliefs about the state of the world. These beliefs can be assumed to be uniform, because all these consumers are precisely in the same situation. Let $\alpha$ denote their probability belief that the world is in state $A$. As producers are uninformed, this belief cannot reasonably depend on producer prices per se. However, the belief can depend on combinations of prices and consumer 1's choice of $a$ or $b$. If

\footnotetext{
${ }^{7}$ Their behavior does not cause a similar externality. They do not possess private information. No one could observe, or would want to, imitate their behavior. One could allow for influence activities with respect to these consumers as well, but this would not change the payoffs as long as these consumers do not have received their own signals.
} 
consumers $i=2, \ldots n$ attribute a probability $\alpha$ to the world being in state $A$, then $\alpha$ and $(1-\alpha)$ are the expected gross benefits for these consumers from purchasing either $a$ or $b$, respectively.

Beliefs must be correct in the equilibrium, but not necessarily out of the equilibrium. Let the consumers $i=2, \ldots n$ assume that $s_{a}=s_{b}$, and that the opinion leader made a rational choice on the basis of her information and the bribes offered to her. The anticipated bribes then 'neutralize' each other. Hence, given that $\theta$ is uniformly distributed and assuming $s_{a}=s_{b}$, they conclude that $\theta \geq 1 / 2$ if she chooses $a$ and that $\theta \leq 1 / 2$ if she chooses b. As $E\left(\theta \mid \theta \geq \frac{1}{2}\right)=\frac{3}{4}$ and $E\left(\theta \mid \theta \leq \frac{1}{2}\right)=\frac{1}{4}$, the consumers' posterior beliefs are

$$
\alpha= \begin{cases}\frac{3}{4} & \text { if } \\ \frac{1}{4} & \text { if } \quad \text { consumer } 1 \text { buys } a \\ & \text { consumer } 1 \text { buys } b\end{cases}
$$

The maximum willingness to pay for each of these consumers (vis-a-vis not buying at all) for product $a$ and $b$ is limited by this value of $\alpha$ and $(1-\alpha)$, respectively. They buy one of the products only if their rent is nonnegative, that is, if $\max \left\{\left(\alpha-p_{a}\right),(1-\alpha)-p_{b}\right\} \geq 0$. In this case they buy $a$ if $\alpha-p_{a}>(1-\alpha)-p_{b}$ and $b$ if $\alpha-p_{a}<(1-\alpha)-p_{b}$. If $\alpha-p_{a}=(1-\alpha)-p_{b}$, they are indifferent. Suppose in this case they buy the product which is more expensive. ${ }^{8}$ If the consumers are indifferent and both products have the same price, consumers may randomize.

Consider now the incentives of the firms to set prices for consumers $i=$ $2, \ldots n$. For a given choice of consumer 1 , and given anticipated values $s_{a}=s_{b}$, the consumers calculate $\alpha$ as in (1). Knowing this, the two firms engage in Bertrand competition. In the equilibrium this leads to a price equal to zero for the firm whose product was not chosen by the opinion leader, and a price equal to $|\alpha-(1-\alpha)|=1 / 2$ for the firm whose product was chosen by the opinion leader, where the last equality follows from (1).

Consider now the choice behavior of the opinion leader. As the noise terms $\epsilon_{a}$ and $\epsilon_{b}$ are set equal to zero, she chooses $a$ if $\theta+s_{a}>(1-\theta)+s_{b}$, or, equivalently, if

$$
\theta>\frac{1}{2}-\frac{s_{a}-s_{b}}{2}
$$

and $b$ if the reverse inequality holds. Equality in (2) is a zero probability event and we can assume any tie-breaking rule for this case without affecting the results.

Consider finally the incentives of the firms to choose bribes. At this stage firm $a$ maximizes the following payoff:

\footnotetext{
${ }^{8}$ This is the tie-breaking rule that that is typically made in Bertrand games with perfect substitutes and asymmetric firms.
} 


$$
\Pi_{a}=\operatorname{prob}\left[\theta+s_{a}>(1-\theta)+s_{b}\right]\left(\frac{n-1}{2}-s_{a}\right) .
$$

This payoff is the product of the probability that the opinion leader chooses $a$ for given bribes $s_{a}$ and $s_{b}$, and the rent that the firm earns if the leader chooses $a$ and, hence, induces all other consumers to choose $a$. Making use of the assumption that $\theta$ is uniformly distributed on $[0,1]$, the probability equals

$$
\operatorname{prob}\left[\theta+s_{a}>(1-\theta)+s_{b}\right]=\left\{\begin{array}{ccc}
0 & \text { if } & s_{b}-s_{a}>1 \\
\frac{1}{2}-\frac{s_{b}-s_{a}}{2} & \text { if } & s_{b}-s_{a} \in[-1,1] \\
1 & \text { if } & s_{b}-s_{a}<-1
\end{array}\right.
$$

The rent obtained in this case equals $n-1$ times the equilibrium price $1 / 2$ charged to consumers $i=2, \ldots n$, minus the bribe that has to be paid to consumer 1 in this case. This makes use of the assumption that the production cost were normalized to zero.

The payoff of firm $b$ is obtained by replacing subscripts $a$ by subscripts $b$.

If the firms simultaneously maximize these payoffs, firms' reaction functions can be obtained from the first-order conditions. Firm a's reaction correspondence is

$$
s_{a}\left(s_{b}\right)=\left\{\begin{array}{ccc}
s_{a} \in\left(-\infty, s_{b}-1\right) & \text { for } & s_{b} \geq \frac{n}{2}+\frac{1}{2} \\
s_{a}=\frac{n}{4}-\frac{3}{4}+\frac{1}{2} s_{b} & \text { for } & s_{b} \in\left[\frac{n}{2}-\frac{7}{2}, \frac{n-1}{2}+\frac{3}{2}\right] . \\
s_{a}=s_{b}+1 & \text { for } & s_{b} \leq \frac{n}{2}-\frac{7}{2}
\end{array}\right.
$$

The second line in (5) represents the first-order condition. For sufficiently large $s_{b}$ it is not optimal for $a$ to offer a bribe that could be accepted with positive probability, but any smaller bribe is optimal. This case is characterized by the first line in (5). For sufficiently small $s_{b}$, it is optimal for $a$ to offer a bribe that is just large enough to make the consumer choose $a$ for all values of $\theta$. In this case $s_{a}=s_{b}+1$ is just sufficient, and this leads to the third line in (5).

The reaction correspondence for firm $b$ is obtained by replacing all subscripts $a$ by $b$ and vice versa. The reaction correspondences overlap or intersect at exactly at one point with $s_{a}=s_{b}=\frac{n-1}{2}-1$ if $n \geq 3$.

Proposition 1 considers a situation with an informed consumer who has the potential of becoming an opinion leader. Firms have an incentive to bribe this consumer to influence the consumer's choice, because her choice can move the whole market. Indeed, if the technology of bribing the opinion leader is fully efficient, that is, if it is just a transfer of money from the firm to the consumer that does not generate any extra cost or noise, the position 
of the opinion leader is very powerful. She captures almost all the producer rent that is generated by all sales to future customers.

The result can be used to address Dichter's (1966) discussion of the problem that firms should try to influence opinion leaders, but that there is a danger that this influence may destroy the channel by which opinion leaders change the market outcome because their judgement or choice becomes less valuable or even useless for those who would like to benefit from their superior information. If firms find efficient ways to bribe the opinion leaders, then their consumer choice is as informative for future consumers as without such bribes. However, at the same time, the market outcome is not very satisfactory from the point of view of producers. They sacrifice all rent on selling to consumers $i=2, \ldots n$ by bribing the informed consumer.

\section{Generalizations and Robustness}

Proposition 1 considers a bechmark case. In what follows I will discuss some of the assumptions of this benchmark case and their importance for the result.

Informed followers. It was assumed in Proposition 1 that consumers $i=$ $2, \ldots n$ are completely uninformed. It is evident in this case that they do not have much to lose by following the opinion leader. This assumption makes herd behavior particularly likely. Even a bit of information obtained from observing the leader's choice is better than no information. Therefore, even if the bribes weakened the opinion leader's signal, this would not make them rely on their own information, because they have none.

Suppose that all consumers $i=2, \ldots n$ also get a signal. Generally, this will complicate the choice of prices $p_{a}$ and $p_{b}$, as consumers $i=2, \ldots n$ will update their beliefs on the basis of the observed behavior of the leader and their own information and the outcome will depend on the characteristics of the signals. Assume, for instance, that all consumers know they received exactly the same signal as the opinion leader with some positive probability $\mu$ and a signal that is simply noise with probability $(1-\mu)$. In this case not much changes. The undistorted leader's action reveals information that is strictly superior to their own information, and not even the problem of choosing $p_{a}$ and $p_{b}$ will be affected in the continuation game in which the leader's choice can be taken as a choice that is fully based on her signal. ${ }^{9}$

\footnotetext{
${ }^{9}$ Admittedly, this conclusion depends on the particular nature of the information signals assumed here. More generally, the equilibrium will depend on how the followers' signals correlate with the opinion leader's signal.
} 
Word-of-mouth. Observing opinion leaders' choices is one way their superior information is transferred to other consumers. The marketing literature emphasizes that opinion leaders' consumption choices are only one channel by which they may transmit their information. Opinion leaders also act as informal advisors for their friends and neighbours. Bribing may then be more or less difficult than if the information transmission occurs via observed consumer choices. On the one hand side, it may take less to bribe someone to give wrong advice, as this does not lead to a personal sacrifice. The advisor does not have to consume the inferior product himself. On the other hand, advice is 'soft' and often not observable or verifiable from the outside. Hence, it may be difficult for the firm that bribes an opinion leader to make sure that the opinion leader really recommends this firm's product. She may take the bribe and then recommend the superior product anyway, particularly if the opinion leader cares about her own reputation in a larger context, or if she feels altruistic with respect to the persons she advises.

To overcome this problem firms will need to monitor the opinion leader, or to make the bribe a function of sales, or to use persuasive advertizing that makes the opinion leader a 'true believer'. Despite these problems, if influence activities are at work, the basic insights from the previous section are also likely to hold if the information is transmitted by 'word of mouth'. Firms will choose symmetric bribes, and hence, the opinion leader's action is still a function of the signal he received.

Typically, in these cases the influence activity cannot be a simple transfer of money. It is then more likely that the effect of the money spent on influence activities is not deterministic, making the influence activity a 'noisy' one. As 'noise' can also have other sources, I consider this aspect in a separate paragraph.

Noise. Suppose that the money value from receiving a bribe is not deterministic. Bribes arrive at the recipient only with some noise. For instance, if the early customers of a new product receive a welcome present, or another in-kind transfer that is produced by the firm, there is some uncertainty about how a customer will value the gift. The valuation could exceed, but will typically fall short of, the cost this gift has for the firm by some amount $\epsilon_{a}$ and $\epsilon_{b}$ for the two firms, respectively, and the deviation may also be difficult to predict for the firm making the gift. Accordingly, the money value received has some element of randomness or noise. For given bribes by firms $a$ and $b$, the relevant noise variable is the difference between $\epsilon_{a}$ and $\epsilon_{b}$.

We consider the case in which consumer 1 can observe the actual value of $s_{i}-\epsilon_{i}$ when she receives the offers for bribes. That is, the consumer knows the 
monetary value she attributes to receiving a particular gift or other benefit, but the firms or other consumers cannot observe these monetary values. ${ }^{10}$

Proposition 2 Let $\epsilon_{A}-\epsilon_{B}$ be uniformly distributed on $[-e, e]$ with $e \leq 1$ and $\epsilon_{a}, \epsilon_{b}>-\frac{1}{2}$. For $n \geq 3$ a perfect Bayesian equilibrium exists such that the firms offer bribes equal to $s_{a}=s_{b}=(n-1)\left[\frac{1}{2}-\frac{e^{2}}{6}\right]-1$ to the opinion leader, the opinion leader chooses the product according to her signal, the consumers $i=2, \ldots n$ choose the same product as the opinion leader and pay a price $p_{j}=\frac{1}{2}-\frac{e^{2}}{6}$.

A proof is in the appendix. Proposition 2 looks at the case in which noise is not very big. The case $e>1$ can be analysed along similar lines and yields qualitatively similar results. The assumption $\epsilon_{a}, \epsilon_{b}>-\frac{1}{2}$ is sufficient to make sure that consumer 1 always accepts one of the equilibrium bribes. It is meant to rule out the uninteresting case in which even a positive bribe is not attractive enough to make the consumer 1 choose one of the products.

Intuitively, Proposition 2 shows that some noise does not change the result of the no-noise case qualitatively. The noise makes the opinion leader's signal less valuable, but does not destroy it. As the signal is less valuable, the profit that is earned from selling to the consumers that follow the leader's choice is lower, and the equilibrium bribe is therefore reduced. Overall there is a welfare loss, as the opinion leader makes the wrong choice more frequently than if she just followed her signal, and the consumers who imitate her behavior replicate this mistake if it occurs.

Deep pockets and liquidity constraints. Let us return to the benchmark case without noise. As shown in Proposition 1, opinion leadership induces firms to make considerable up-front payments when trying to attract the whole market. Firms spend all their future profit on early customers who influence later consumers. These up-front payments require 'deep pockets'. A firm that is liquidity constrained cannot spend all of its future profits or a major share of them in a market on initial campaigns, advertisement and consumer discounts.

There are two issues one can look at. Consider first a symmetric case in which the two firms are equally liquidity constrained and unable to offer the unconstrained equilibrium bribe. They will both offer the maximum possible bribe. As long as this is correctly anticipated by the consumers $i=2, \ldots n$, it will not affect the pricing game, but the early consumer will receive a smaller

\footnotetext{
${ }^{10}$ The case in which the actual value of $\epsilon_{i}$ is revealed to the consumer only when the true state of nature is also revealed is less interesting, as the consumer 1 will make its choice on the basis of expecteed values of $\epsilon_{i}$, and this basically eliminates the noise problem.
} 
bribe. Hence, if both firms are liquidity constrained, this benefits the firms and harms the early consumer.

Consider asymmetric liquidity constraints. Let one firm be liquidity constrained, and let the other firm have deep pockets. In this case the bribes offered by the firms will not necessarily be symmetric, leading to distorted consumption decisions by consumer 1 . In turn, this will change the information that can be extracted from consumer 1's choice. It will turn out that this makes influence activities less effective and reduces, but does not eliminate, the rent transfer to consumer 1 . It is also interesting to ask whether a unilateral liquidity constraint is a strategic advantage or a disadvantage.

Proposition 3 Let firm $b$ be cash constrained to $s_{b} \leq 0$ and firm $a$ be unconstrained. Let $n \geq 3$ and $\epsilon_{a}=\epsilon_{b}=0$. Then there is a perfect Bayesian equilibrium with $s_{a}=\frac{n-3}{n+3}$ and $s_{b}=0$. The resulting expected profits are $\frac{2 n^{2}}{(n+3)^{2}}$ for firm $a$ and $\frac{3 n^{2}-3 n}{(n+3)^{2}}$ for firm $b$. The sum of all rents is lower than if $b$ is not liquidity constrained.

A proof and a calculation of consumer 1's rent are in the appendix. Intuitively, firm $a$ can choose a positive subsidy such that the first consumer chooses product $a$ with a probability that is higher than one half, and the firm has an incentive to do this. However, the consumers $i=2, \ldots n$ anticipate the optimal bribe, and that for this bribe the choice of $a$ reveals an information about $\theta$ that differs from the symmetric case. In some cases in which, disregarding the bribe, the consumer had a mild preference for $b$ consumer 1 still chooses $a$. This reduces the value of the first consumer's choice $a$ as a signal, whereas the choice of $b$ becomes an even more valuable signal. Accordingly, firm $a$ 's bribe has a positive externality for firm $b$, as it increases this firm's equilibrium price. Overall, both firms benefit from this unilateral bribes, but firm $b$ benefits from $a$ 's influence activities by even more than firm $a$. Firm $b$ ends up with a payoff even higehr than the unconstrained firm's payoff for all $n>3$.

The asymmetry and the 'wrong' decision this asymmetry causes with respect to some of consumer 1's choices also cause an inefficiency, and the herd behavior of all other consumers magnifies this inefficiency.

Endogenous leadership. It is plausible to assume that opinion leaders already exist in a society and are exogenously given for a firm that innovates a new product. However, as opinion leaders capture a large share of rents, members in a society have an incentive to become opinion leaders and may have some instruments for achieving this goal. The marketing literature has 
studied the various determinants of opinion leadership. Some of these determinants are social independence and social integration (Wilkie 1986) and are not really a matter of choice, or at least difficult to change in the short run. ${ }^{11}$ Another determinant that is well documented to be an important determinant for a consumer to become and act as an opinion leader is the consumer's information or expertise (Grewal, Mehta and Kardes 2000), and this variable is most obviously endogenous from the point of view of a consumer. Accordingly, at least some persons should have considerable incentives to acquire information in a society in which opinion leadership matters and generates a leadership rent. The information acquisition process may dissipate some or all of the opinion leaders' expected rent. But the incentive to acquire information will also contribute to overcoming the market inefficiency that is typically associated with the public good property of consumers' product information.

\section{Discussion}

This paper considers markets in which some consumers have an information advantage about product quality. Such consumers could choose early and, if their choice is publicly observed, act as opinion leaders and generate herd behavior on the part of other consumers. Firms that compete for customers also know which consumer has an information advantage and could therefore act as an opinion leader. They may therefore approach these consumers and try and influence the leader's choice by bribes. In this paper I show that efficient bribes do not affect the opinion-leader's choice in the equilibrium. Hence, her choice has the same value as a signal to further consumers as in the absence of bribes. However, the bribes shift almost all rent away from the firms and to the opinion leader.

Bribes could potentially distort the signal that the leader's choice could otherwise give to further consumers. In this paper I show that this becomes indeed a problem if bribes involve noise. Noise can then reduce the quality of the opinion leader's choice as a signal. This leads to less efficient market outcomes in which the followers make an inefficient product choice more frequently, in which the opinion leader receives lower bribes and also the firms may have lower profits in the equilibrium.

Also, asymmetry of firms, e.g., with respect to liquidity constraints, can cause a welfare loss if these firms may use bribes to influence opinion lead-

\footnotetext{
${ }^{11}$ In the medium or long run individuals also make a choice and optimize on their social and communication network as has been discussed, e.g., in the context of information diffusion (see, e.g., Granovetter 1973, Burt 1992).
} 
ers' consumption choice, and these inefficiencies are magnified by the herd behavior that is induced by the opinion leaders' choice.

Summarizing, the market outcome with opinion leaders and influence activities puts opinion leaders in a fortunate position. They extract huge rents. Accordingly, the position as opinion leader is very attractive. In turn, this may induce individuals to make investments in information acquisition, and in activities by which they credibly reveal having made these investment choices. To some extent this effect may counteract the inefficiencies that may prevail otherwise in markets in which product quality is unknown and investments need to be made in learning product quality.

\section{Appendix}

Proof of Proposition 2: Consider first the consumers $i=2, \ldots n$. Their expected payoffs from buying good $a$ or $b$ depends on their posterior beliefs about the state of the world. These beliefs can be assumed to be identical for all $i=2, \ldots n$, because all these consumers are in the same situation. Let $\alpha$ again denote their probability belief of the world being in state $A$. Then $\alpha$ and $(1-\alpha)$ are the expected benefits for a consumer from purchasing either $a$ or $b$, respectively.

Let the consumers believe that $s_{a}=s_{b}$ as before, that consumer 1 made a rational choice on the basis of her information and the bribes offered to her, where the actual bribes are not observed by $i=2, \ldots n$. Consider their expectations. Consumer 1 will choose $a$ if

$$
\left(\theta+s_{a}-\epsilon_{a}\right)-\left[(1-\theta)-s_{b}-\epsilon_{b}\right]>0
$$

and $b$ if the reverse inequality holds, ${ }^{12}$ if the participation constraint $\max \{(\theta+$ $\left.\left.s_{a}-\epsilon_{a}\right),\left(1-\theta-s_{b}-\epsilon_{b}\right)\right\} \geq 0$ is fulfilled. This constraint can be disregarded, given the limits that are imposed on $\epsilon_{a}$ and $\epsilon_{b}$ in the proposition. I do not consider this in detail here.

If consumers $i=2, \ldots n$ expect $s_{a}=s_{b}$, then, also using the assumptions about uniform and stochastically independent distributions of $\theta$ and of $\left(\epsilon_{a}-\epsilon_{b}\right)$, they calculate $\alpha$ given that the opinion leader chooses $a$ and $b$, respectively, as follows.

Consider $E\left(\theta \mid 2 \theta-1>\epsilon_{a}-\epsilon_{b}\right)$. Recall that $\theta$ is uniformly distributed on the interval $[0,1]$ and $\epsilon_{a}-\epsilon_{b}$ is uniformly distributed on the interval $[-e,+e]$ with $e \leq 1$, and $\theta$ and $\epsilon_{a}-\epsilon_{b}$ are stochastically independent. Define

\footnotetext{
${ }^{12}$ For equality, again any tie-breaking rule will not affect the results, as this is a zeroprobability event.
} 
$x=(2 \theta-1)$. Then

$$
\left.\left.E\left(\frac{x+1}{2} \mid x>\epsilon_{a}-\epsilon_{b}\right)\right)=\frac{1}{2}+\frac{1}{2} E\left(x \mid x>\epsilon_{a}-\epsilon_{b}\right)\right) .
$$

Now consider

$$
\begin{aligned}
\left.E\left(x \mid x-\left(\epsilon_{a}-\epsilon_{b}\right)>0\right)\right) & =\frac{1}{2 e}\left(\int_{-e}^{+e} x(e+x) d x+\int_{+e}^{1}(x 2 e) d x\right) \\
& =\frac{1}{2 e}\left[\frac{e x^{2}}{2}+\frac{x^{3}}{3}\right]_{-e}^{+e}+\left[\frac{2 e x^{2}}{2}\right]_{+e}^{1} \\
& =\frac{1}{2 e}\left(\frac{2 e^{3}}{3}+\left(e-e^{3}\right)\right) \\
& =\frac{1}{2}-\frac{e^{2}}{6} .
\end{aligned}
$$

Accordingly, $\left.E\left(\theta \mid 2 \theta-1>\left(\epsilon_{a}-\epsilon_{b}\right)\right)\right)=\frac{1}{2}+\frac{1}{2}\left(\frac{1}{2}-\frac{e^{2}}{6}\right)=\frac{3}{4}-\frac{e^{2}}{12}$. Consumers $i=2, \ldots n$ will use this as their updated belief about the probability of the states of nature:

$$
\alpha=\left\{\begin{array}{l}
\left.E\left(\theta \mid 2 \theta-1>\epsilon_{a}-\epsilon_{b}\right)\right)=\frac{3}{4}-\frac{e^{2}}{12} \quad \text { if } \quad \text { consumer } 1 \text { buys } a \\
\left.E\left(\theta \mid 2 \theta-1<\epsilon_{a}-\epsilon_{b}\right)\right)=\frac{1}{4}+\frac{e^{2}}{12} \quad \text { if } \quad \text { consumer } 1 \text { buys } b
\end{array}\right.
$$

Note that this $\alpha$ converges towards $3 / 4$ and $1 / 4$ for $e \rightarrow 0$. The maximum willingness to pay for each of these consumers (vis-a-vis not buying at all) for product $a$ and $b$ is equal to $\alpha$ and $(1-\alpha)$, respectively. Consumers buy exactly one of the products if at least one of the prices $p_{a}$ or $p_{b}$ falls short of the respective critical limit. Accordingly, they buy $a$ if $\alpha-p_{a}>(1-\alpha)-p_{b}$ and $b$ if the reverse inequality holds. Again I adopt the tie-breaking rule that is standard in asymmetric Bertrand games that, if equality holds, they all choose the product with the higher price. If equality holds and both products have the same price, they randomize.

Consider now the incentives of the firms to set prices for consumers $i=$ $2, \ldots n$ given the expectations as in (9). The two firms engage in Bertrand competition. This leads to a price equal to zero for the firm whose product was not chosen by consumer 1 , and a price equal to $|\alpha-(1-\alpha)|=\frac{1}{2}-\frac{e^{2}}{6}$ for the firm whose product was chosen by consumer 1 .

Consider next the choice behavior of consumer 1 . She chooses $a$ if $\theta+$ $s_{a}-\epsilon_{a}>(1-\theta)+s_{b}-\epsilon_{b}$, or, equivalently, if

$$
\theta>\frac{1}{2}-\frac{s_{a}-s_{b}-\left(\epsilon_{a}-\epsilon_{b}\right)}{2} .
$$


The opinion leader chooses $b$ if the reverse inequality holds. The case of equality is a zero probability event and we can adopt any tie-breaking rule for this case, without affecting the results.

Consider finally the incentives of the firms to choose bribes. Firm $a$ 's payoff is zero if consumer 1 chooses $b$. Firm $a$ earns $n-1$ times the equilibrium price $p_{a}=\frac{1}{2}-\frac{e^{2}}{6}$ from selling to consumers $i=2, \ldots n$ if consumer 1 chooses product $a$, and has the cost of the bribe $s_{a}$ in this case. This happens with a probability

$$
\begin{aligned}
\pi_{a}\left(s_{a}, s_{b}\right)= & \operatorname{prob}\left[(2 \theta-1)+\left(s_{a}-s_{b}\right)>\left(\epsilon_{a}-\epsilon_{b}\right)\right] \\
= & \left\{\begin{array}{clc}
0 & \text { if } & s_{a}-s_{b}<-(1+e) \\
\frac{\left(1+e+\left(s_{a}-s_{b}\right)\right)^{2}}{8 e} & \text { if } & s_{a}-s_{b} \in[-(1+e),-(1-e)] \\
\frac{1}{2}+\frac{s_{a}-s_{b}}{2} & \text { if } & s_{a}-s_{b} \in[-(1-e),(1-e)] \\
1-\frac{\left(1+e-\left(s_{a}-s_{b}\right)\right)^{2}}{8 e} & \text { if } & s_{a}-s_{b} \in[1-e, 1+e] \\
1 & \text { if } & s_{a}-s_{b}>1+e
\end{array}\right.
\end{aligned}
$$

Accordingly, firm a's payoff can be written as

$$
\Pi_{a}\left(s_{a}, s_{b}\right)=\pi_{a}\left(s_{a}, s_{b}\right)\left((n-1)\left(\frac{1}{2}-\frac{e^{2}}{6}\right)-s_{a}\right) .
$$

The payoff of firm $b$ is obtained by replacing all subscripts $a$ by $b$ and vice versa. Maximization of these payoffs yields first-order conditions that have a symmetric solution with

$$
s_{a}=s_{b}=(n-1)\left[\frac{1}{2}-\frac{e^{2}}{6}\right]-1 .
$$

Proof of Proposition 3: Consider first the consumers $i=2, \ldots n$. Let them anticipate bribes $s_{a}^{*}=\frac{n-3}{n+3}$ and $s_{b}^{*}=0$. Taking these values they calculate their maximum willingnesses to pay for $a$ and $b$, depending on the consumer 1's choice. This consumer is expected to choose $a$ if

$$
\theta+s_{a}^{*}>(1-\theta)+s_{b}^{*}
$$

Using $s_{b}^{*}=0$ and the assumption that $\theta$ is uniformly distributed on $[0,1]$, the expected value of good $a$ for a consumer $i=2, \ldots n$ if consumer 1 chooses $a$ then equals $\frac{1}{2}\left(1+\left(\frac{\left.1-s_{a}^{*}\right)}{2}\right)\right)=\frac{3}{4}-\frac{s_{a}^{*}}{4}$. Similarly, if the reverse inequality holds, consumer 1 chooses $b$. The expected value of $a$ for the consumers $i=2, \ldots n$ is $\frac{1}{4}-\frac{s_{a}^{*}}{4}$ in this case. Note that the minus sign here is not by mistake. If 
only firm $a$ chooses a positive bribe, this decreases $\alpha$ below $\frac{1}{4}$ if consumer 1 actually chooses $b$. Hence,

$$
\alpha=\left\{\begin{array}{l}
\frac{3}{4}-\frac{s_{a}^{*}}{4}=\frac{3}{4}-\frac{1}{4} \frac{n-3}{n+3} \quad \text { if } \quad \text { consumer } 1 \text { buys } a \\
\frac{1}{4}-\frac{s_{a}^{*}}{4}=\frac{1}{4}-\frac{1}{4} \frac{n-3}{n+3} \quad \text { if } \quad \text { consumer } 1 \text { buys } b .
\end{array}\right.
$$

Turning to the firms' choices of $p_{a}$ and $p_{b}$, suppose first consumer 1 chose $a$. Firm $b$ will choose $p_{b}=0$ and firm $a$ will charge the maximum difference that the consumers are willing to pay for $a$ instead of $b$. This difference is $p_{a}=2 \alpha-1=\frac{1}{2}-\frac{s_{a}^{*}}{2}$. This shows that an increase in $a$ 's bribe increases the probability that consumer 1 chooses $a$, but decreases the equilibrium price that firm $a$ can charge to all subsequent consumers in this case. This causes a trade-off for firm $a$.

If consumer 1 chose $b$, then the other consumers believe that $\alpha=\frac{1}{4}-\frac{s_{a}^{*}}{4}$. Firm $a$ chooses $p_{a}=0$ and firm $b$ chooses $p_{b}=1-2 \alpha=\frac{1}{2}+\frac{s_{a}^{*}}{2}$. It is interesting to note that the price that firm $b$ can charge once consumer 1 has chosen $b$, is higher the higher the bribe chosen by firm $a$. Hence, an increase in $a$ 's bribe decreases the probability that $b$ is chosen, but increases the price that $b$ can charge to all other consumers in this case.

Consumer 1's choice has already been considered implicitly above.

Coming to the firm's choice of bribes, the payoff of firm $a$ is

$$
\Pi_{a}=\left(\frac{1}{2}+\frac{s_{a}}{2}\right)\left((n-1)\left(\frac{1}{2}-\frac{s_{a}^{*}}{2}\right)-s_{a}\right) .
$$

Maximization of $\Pi_{a}$ with respect to $s_{a}$ for $s_{b}=0$ leads to a first order condition $\frac{1}{4} n-\frac{1}{4} n s_{a}^{*}-\frac{3}{4}+\frac{1}{4} s_{a}^{*}-s_{a}=0$. The implicit function $s_{a}\left(s_{a}^{*}\right)$ that determines firm $a$ 's optimal bribe as a function of the anticipated bribe offer has a single fixed point

$$
s_{a}^{*}=\frac{n-3}{n+3} .
$$

Finally note that $s_{b}^{*}=0$ is optimal among all $s_{b} \leq 0$ for this given choice of $s_{a}^{*}$ and anticipated choice of $s_{b}^{*}=0$ by the consumers $i=2, \ldots n$. The profit of firm $b$ is given in this case as

$$
\Pi_{b}=\left(\frac{1}{2}+\frac{s_{b}-\frac{n-3}{n+3}}{2}\right)\left((n-1)\left(\frac{1}{2}+\frac{1}{2} \frac{n-3}{n+3}\right)-s_{b}\right) .
$$

Accordingly, $\frac{d \Pi_{b}\left(s_{b}, s_{a}^{*}\right)}{d s_{b}}=\frac{1}{2} \frac{n^{2}-n-2 s_{b} n-6 s_{b}-6}{n+3}>0$ for all $s_{b}<0$ and $n \geq 3$. Hence, among the bribe offers that are feasible for this firm, $b$ would want to choose the maximum bribe $s_{b}^{*}=0$. 
These equilibrium bribes can be used to calculate the equilibrium payoffs of the different players. The expected profit of firm $a$ becomes

$$
\Pi_{a}^{*}=\frac{2 n^{2}}{(n+3)^{2}} .
$$

The profit of firm $b$ becomes

$$
\Pi_{b}^{*}=\frac{3(n-1) n}{(n+3)^{2}} .
$$

Accordingly, the liquidity constrained firm $b$ has a higher profit than the unconstrained firm $a$ for all $n>3$.

Consumer 1's payoff equals

$$
\begin{aligned}
& \left(\frac{1}{2}-\frac{1}{2} \frac{n-3}{n+3}\right) \times E\left((1-\theta) \mid \theta<\left(\frac{1}{2}-\frac{1}{2} \frac{n-3}{n+3}\right)\right)+ \\
& {\left[1-\left(\frac{1}{2}-\frac{1}{2} \frac{n-3}{n+3}\right)\right] \times\left(E\left(\theta \mid \theta>\left(\frac{1}{2}-\frac{1}{2} \frac{n-3}{n+3}\right)\right)+\frac{n-3}{n+3}\right)}
\end{aligned}
$$

Simplifying yields $\frac{3}{2} \frac{n^{2}+2 n+3}{(n+3)^{2}}$ which is equal to $\frac{3}{4}$ as in proposition 1 , and strictly less than consumer 1's rent in proposition 1 for all $n>3$. All other consumers receive their willingness to pay for the supposedly inferior product, which equals $(1-\alpha)=\frac{1}{2} \frac{n}{n+3}$ if consumer 1 chooses $a$, and equal to $\alpha=\frac{3}{2(n+3)}$ if consumer 1 chooses $b$.

The reduction in aggregate welfare results from the fact that consumer 1 chooses $a$ with a positive probability even if $\theta<\frac{1}{2}$ in this equilibrium, and all other consumers even imitate this inefficient choice.

\section{References}

Bannerjee, A.V., 1992, A simple model of herd behavior, Quarterly Journal of Economics, 107(3), 797-817.

Bikhchandani, Sushil, David Hirshleifer and Ivo Welch, 1992, A theory of fads, fashion, custom, and cultural change as informational cascades, Journal of Political Economy, 100(5), 992-1026.

Bliss, Christopher, and Barry Nalebuff, 1984, Dragon-slaying and Ballroom Dancing: The Private Supply of a Public Good, Journal of Public Economics, 25(1-2), 1-12.

Burt, Ronald, 1992, Structural Holes, Harvard University Press, Cambridge, MA. 
Dichter, Ernest, 1966, How word-of-mouth advertising works, part I, Harvard Business Review, 1966(November/December), 147-157.

Granovetter, Mark, 1973, The strength of weak ties, American Journal of Sociology, 78, 1360-1380.

Grewal, Rajdeep, Raj Mehta and Frank R. Kardes, 2000, The role of the social-identity function of attitudes in consumer innovativeness and opinion leadership, Journal of Economic Psychology, 21, 233-252.

Leonard-Barton, Dorothy, 1981, The diffusion of active residential solar energy equipment in California, in: Avraham Shama (ed.), Marketing Solar Energy Innovations, Praeger, New York, 145-183.

Rogers, Everett M., 1983, Diffusion of innovations, The Free Press, New York.

Valente, Thomas W. and Rebecca L. Davis, 1999, Accelerating the diffusion of innovations using opinion leaders, Annals of the American Academy of Political and Social Science, 566, 55-67.

Wilkie, Wiliam L., 1986, Consumer behavior, John Wiley and Sons, New York. 